\title{
BIOLOGICAL ACTIVITY OF ß-GLUCANS FROM EDIBLE MUSHROOM, SCHIZOPHYLLUM COMMUNE IN THAILAND
}

\author{
SAMRAJ RATTANADILOK N. A. PHUKET, TITIMA SANGKAEW, PIYATIDA CHANAPAN, SURACHAI \\ TECHAOEI*
}

Thai Traditional Medicine College, Rajamangala University of Technology Thanyaburi, Pathum Thani, Thailand. Email: surachai_te@rmutt.ac.th

\begin{abstract}
Received: 17 December 2018, Revised 10 February 2019 and Accepted: 16 February 2019

Objective: The objective of this research was to determine the antioxidant of ß-glucans from an edible mushroom, Schizophyllum commune in Thailand.

Methods: The antioxidant activity of $\beta$-glucans was measured in terms of hydrogen donating or radical scavenging ability by 2, 2-diphenyl-1picrylhydrazyl (DPPH) method,2,2'-azinobis-(3-ethyl-benzothiazoline-6-sulfonic acid (ABTS) radical scavenging activity analysis, and total phenolic compounds. The ß-glucans structure was analyzed using Fourier-transform infrared spectrophotometer.
\end{abstract}

Results: The ß-glucans were extracted from S. commune and tested biological activities. Using the Folin-Ciocalteu Reactive method, we found that

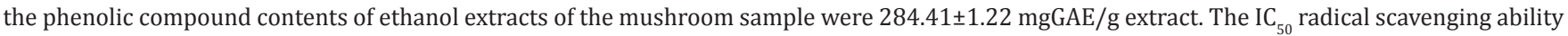
$(\mathrm{DPPH})$ and $\mathrm{IC}_{50}$ radical scavenging activity (ABTS) of $ß$-glucans were $0.829 \pm 0.006$ and $0.724 \pm 0.021 \mathrm{mg} / \mathrm{mL}, \mathrm{respectively}$.

Conclusion: The ß-glucans from S. commune in Thailand showed a potent antioxidant activity and it will be able to apply in pharmaceutical cosmetics.

Keywords: Schizophyllum commune, Antioxidant activity, ß-glucans, Edible mushroom.

(C) 2019 The Authors. Published by Innovare Academic Sciences Pvt Ltd. This is an open access article under the CC BY license (http://creativecommons. org/licenses/by/4. 0/) DOI: http://dx.doi.org/10.22159/ijap.2019.v11s5.T0083

\section{INTRODUCTION}

The edible mushrooms are a natural product of the forest environment that grows on the most abundant nutrients such as cellulose [1]. They are a macro-fungus that has a distinctive fruiting body, have been mostly used as human food for centuries and have been famous for texture and flavor as well as having various medicinal properties [1,2]. However, in recently emerged, the edible mushrooms, as being an important source of biologically active material, have medicinal value. Mushrooms are rich in different biologically active compounds such as phenolics, tocopherol, lycopene, ß-carotene, vitamins, polysaccharide, and secondary metabolites in their fruiting bodies [3].

The edible mushrooms are the sources of bioactive substances such as secondary metabolites, have become attractive as a functional food which related to the beneficial health effects, antioxidants in biological systems [4]. It has been reported to interfere with the initiation and progression of tumor cell [5], antiaging [6], anti-inflammatory [7], brainprotective factors, and to protect against cardiovascular disease [8].

Hence, the present study primarily focused on the selection of solvents for extraction and analysis of antioxidant activities of Schizophyllum commune from Thailand. The results will be beneficial for pharmaceutical application and drug developments as well as the cosmetic industry. Consequently, it may be part of alternative antioxidant resources instead of synthetic antioxidant.

\section{METHODS}

\section{Fungal strain}

S. commune-producing ß-glucans strain used in this study was S. commune, which obtained from Thai Traditional Medicine College, Rajamangala University of Technology Thanybauri, Pathum Thani, Thailand.
Inoculum preparation

S. commune was initially grown on Potato dextrose agar (PDA) in a Petri dish and then incubated at $30^{\circ} \mathrm{C}$ for 7 days.

\section{Culture conditions}

The flask culture experiments were performed in $250 \mathrm{ml}$ Erlenmeyer flask that contained $50 \mathrm{ml}$ of media. The five plugs of the seed culture were transferred into the culture medium and then inoculated at $30^{\circ} \mathrm{C}$ for 7 days.

\section{Production of polysaccharide}

S. commune was initially grown on optimal condition in a $500 \mathrm{ml}$ flask at $30^{\circ} \mathrm{C}$ on a rotary shaker incubator at $150 \mathrm{rpm}$ for 7 days.

\section{Extraction of polysaccharide}

The fermentation broth was centrifuged at $8000 \mathrm{~g}$ for $20 \mathrm{~min}$, and the resulting supernatant was filtered through Whatman filter paper No. 2 and mixed with four volumes of absolute ethanol, stirred vigorously, and left overnight at $4^{\circ} \mathrm{C}$. The precipitate polysaccharide was collected by centrifugation at $8000 \mathrm{~g}$ for $10 \mathrm{~min}$. The residue was reprecipitated with the same volume of ethanol, and the precipitate of pure polysaccharide was freeze-dried in a lyophilizer.

Preparation of $\beta$-glucan extracts solution to determine the antioxidant activity

Accurate weight of $0.1 \mathrm{~g}$ of the $\beta$-glucan extracts was dissolved in $5 \mathrm{ml}$ dimethyl sulfoxide (Merck, Germany) and dilute to $250 \mathrm{~mL}$ of $99 \%$ methanol. This solution is to determine the total phenolic content, 2, 2-diphenyl-1-picrylhydrazyl (DPPH) and ABTS radical scavenging activity.

Determination of total phenolic compounds

The total amount of phenolic compounds was determined with a modified standard Folin-Ciocalteu reagent [9]. Briefly, the $0.1 \mathrm{~mL}$ of the sample solution, $2 \mathrm{~mL}$ of the Folin-Ciocalteu reagent (Merck, Germany), and $1.5 \mathrm{ml}$ of $2 \%$ sodium carbonate were mixed on a vortex mixer. After $30 \mathrm{~min}$ reaction, the absorbance at $765 \mathrm{~nm}$ was determined 
and used to estimate the phenolic content using the calibration curve made with gallic acid (Merck, Germany). The total amount of phenolic compounds was expressed in $\mu$ g gallic acid equivalent per g dry weight of extractions.

\section{ABTS radical scavenging activity analysis}

The antioxidant activity was measured using a modified version [10]. To prepare ABTS cation radical solution, $2.45 \mathrm{mM}$ of potassium persulphate (Merck, Germany) aqueous solution was added to $7 \mathrm{mM}$ of ABTS (Sigma-Aldrich, Germany) in equal quantities and allowing them to react for $24 \mathrm{~h}$ at room temperature in the dark. One $\mathrm{mL}$ of the final dark-green radical solution was then diluted with $60 \mathrm{ml}$ methanol and used in ABTS tests. $0.1 \mathrm{~mL}$ of different concentrations of the $\beta$-glucan extracts solution were added to $2 \mathrm{~mL}$ of ABTS $+\bullet$ solution. The mixtures were incubated at room temperature, in the dark for $6 \mathrm{~min}$ before reading the absorbance against a blank at $734 \mathrm{~nm}$ using UV-Vis GENESYS 10S spectrometer (Thermo Fisher Scientific, USA). Inhibition of free radical by ABTS in percent (I\%) was calculated in the following way:

Scavenging Inhibition $(I \%)=\left(A_{\text {blank }}-A_{\text {sample }} / A_{\text {blank }}\right) \times 100$

where, $\mathrm{A}_{\text {blank }}$ is the absorbance of the control reaction (containing all reagents except the test compound) and $A_{\text {sample }}$ is the absorbance of the test compound. The value of $50 \%$ inhibition $\left(\mathrm{IC}_{50}\right.$ ) was calculated from the graph plotted inhibition percentage against extract concentrations. Tests were carried out in triplicate. In the ABTS assay, Trolox was used as a positive control.

\section{DPPH radical scavenging activity analysis}

The radical scavenging activity of $\beta$-glucans was conducted using the modified method [10]. Different concentration of extract solutions $(0.1 \mathrm{~mL})$ was added to $3.0 \mathrm{~mL}$ of $0.1 \mathrm{mM}$ methanol solutions of DPPH (Sigma-Aldrich, Germany). The samples were first kept in the dark place at room temperature, and after $30 \mathrm{~min}$, the absorbance was measured at $517 \mathrm{~nm}$ using a spectrophotometer. The percent of inhibition and the value of $50 \%$ inhibition $\left(\mathrm{IC}_{50}\right.$ ) were calculated the same as ABTS radical scavenging activity test.

\section{Chemical analysis of $\boldsymbol{\beta}$-glucans}

Infrared spectroscopy was performed with equipment from Perkin Elmer, model spectrum RX. The method used was an FT-IR in $\mathrm{KBr}$ solid. The KBr was pulverized in an agate mortar and pestle, and the sample, which was also sprayed together with $\mathrm{KBr}$, was added. With the resulting powder, a tablet was made by compression with a pressure of 10 tons.

\section{RESULTS AND DISCUSSION}

\section{Total phenolic content and antioxidant activity of $\beta$-glucan}

Phenolic compounds as a large group of biologically active molecule present in mushroom species [11]. Besides, their antioxidant activities, phenolics exhibit anti-inflammatory, and antimicrobial activity. Total phenolic content, antioxidant activity of $\beta$-glucans from $S$. commune, is shown in Table 1 . This result showed a total phenolic of $284.41 \pm 1.22 \mathrm{mgGAE} / \mathrm{g}$ extract. The results indicating that ethanol was the suitable solvent for phenolic form $S$. commune. The antioxidant activity of methanolic extract of $S$. commune was subjected to DPPH and ABTS effect of the extract. ABTS activity was quantified in terms of percentage inhibition of the ABTS •+ radical cation by antioxidants in plant sample, as an oxidizing agent to the evaluated antioxidant activity of biological samples. Table 1 showed the $\mathrm{IC}_{50}$ of ABTS scavenging activity and DPPH scavenging activity of $0.829 \pm 0.006$ and $0.724 \pm 0.021 \mathrm{mg} / \mathrm{ml}$, while Trolox showed the $\mathrm{IC}_{50}$ of ABTS scavenging activity and $\mathrm{DPPH}$ scavenging activity of $0.128 \pm 0.009$ and $0.116 \pm 0.009$, respectively. This experimental result was similar to the previous reported [12].

\section{Chemical analysis of $\beta$-glucans from $S$. commune}

Infrared spectroscopy allows the measurement of molecular vibrations of covalent bonds. The infrared region $3900-400 \mathrm{~cm}^{-1}$ provides
Table 1: Total phenolics and $\mathrm{IC}_{50}$ values obtained for the antioxidant activity of the $\beta$-glucan extracted

\begin{tabular}{|c|c|c|c|}
\hline \multirow{2}{*}{$\begin{array}{l}\beta \text {-glucans } \\
\text { extracted }\end{array}$} & \multirow{2}{*}{$\begin{array}{l}\text { Total phenolic } \\
\text { (mgGAE/g extract) }\end{array}$} & \multicolumn{2}{|l|}{$\mathrm{IC}_{50}(\mathrm{mg} / \mathrm{mL})$} \\
\hline & & $\begin{array}{l}\text { ABTS } \\
\text { scavenging } \\
\text { activity }\end{array}$ & $\begin{array}{l}\text { DPPH } \\
\text { scavenging } \\
\text { activity }\end{array}$ \\
\hline$\beta$-glucans & $284.41 \pm 1.22$ & $0.829 \pm 0.006$ & $0.724 \pm 0.021$ \\
\hline Trolox & . & $0.128 \pm 0.009$ & $0.116 \pm 0.009$ \\
\hline
\end{tabular}

GAE: Gallic acid equivalent, DPHH: 2, 2-diphenyl-1-picrylhydrazyl

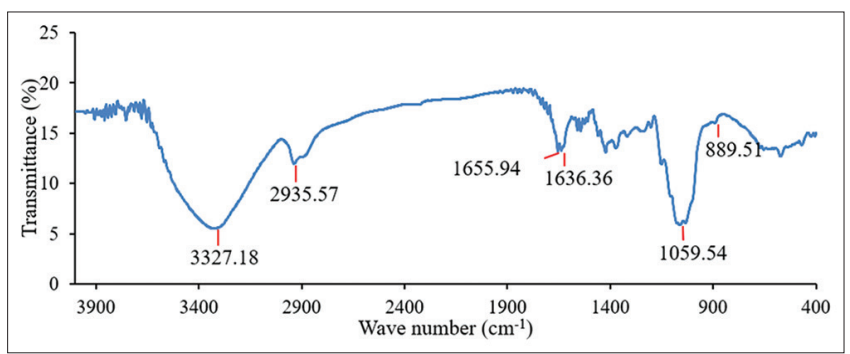

Fig. 1: Infrared spectra of $\beta$-glucan in the sample extracted

information on the fundamental vibrations. The infrared spectra of extracted $\beta$-glucan are shown in Fig. 1.

In the region of $3700-3000 \mathrm{~cm}^{-1}$, the extracted $\beta$-glucans spectra showed a wide band with maximum absorption at $3327 / \mathrm{cm}$. This can be attributed to normal vibrational modes of asymmetric and symmetric stretching of $\mathrm{OH}$ groups because polysaccharides contain a significant number of $\mathrm{OH}$ groups, which exhibit an absorption band above $3000 / \mathrm{cm}[13,14]$.

The absorption peaks occurring at $2935 / \mathrm{cm}$ in the region of 2900- $2400 \mathrm{~cm}^{-1}$ could be attributed to therelativevalues of the vibrational modes of asymmetric and symmetric stretches of $\mathrm{CH}$ groups [15].

The absorption at $1655 / \mathrm{cm}$ and $1636 / \mathrm{cm}$ was due to the stretching of $\mathrm{CN}$ groups and $\mathrm{NH}$ groups of the proteins indicating the presence of amide linkages and the presence of protein in the sample $[15,16]$. These results are in accordance with the chemical evaluation, indicating the presence of protein in the sample.

The region 1400-400 $\mathrm{cm}^{-1}$, which showed peaks with maximum absorption at $1059 / \mathrm{cm}^{-1}$, corresponds to COC and CO bonds of a ring of D-glucose [16]. It is also important to note that the spectra showed absorption peaks at $889 / \mathrm{cm}$, which is indicative of $\beta$-glycosidic bonds $[17,18]$.

\section{CONCLUSION}

In this study, we determined the antioxidant activities and $\beta$-glucan content of edible mushroom species, $S$. commune. Based on the results, the $ß$-glucans extracts from $S$. commune showed a potent antioxidant activity, and it will be able to apply in pharmaceutical cosmetics.

\section{ACKNOWLEDGMENT}

We are grateful to Thai Traditional Medicine College, Rajamanagala University of Thanyaburi (Rangsit center) for all facilities and we are also thankful to our advisor, Dr. Surachai Techaoei for providing necessary facilities during the study.

\section{REFERENCES}

1. Chandrawanshi NK, Tandia DK, Jadhav SK. Nutraceutical properties evaluation of Schizophyllum commune. Indian J Sci Res 2017;13:57-62. 2. Devi LS, Dasgupta A, Chankraborty M, Borthakur SK, Singh NI. 
Chemical composition and antioxidant activity of Schizophyllum commune. Int J Pharm Sci Rev Res 2014;27:173-7.

3. Robaszkiewicz A, Bartosz G, Lawrynowicz M, Soszynski M. The Role of polyphenols, $\beta$-Carotene, and lycopene in the antioxidative action of the extracts of dried, edible mushrooms. J Nutr Metab 2010;11:1-9.

4. Barros L, Venturini BA, Baptista P, Estevinho LM, Ferreira IC. Chemical composition and biological properties of Portuguese wild mushrooms: A comprehensive study. J Agric Food Chem 2008;56:3856-62.

5. Chen D, Dou QP. Tea polyphenols and their roles in cancer prevention and chemotherapy. Int J Mol Sci 2008;9:1196-206.

6. Markus MA, Morris BJ. Resveratrol in prevention and treatment of common clinical conditions of aging. Clin Interv Aging 2008;3:331-9.

7. Rahman I, Biswas SK, Kirkham PA. Regulation of inflammation and redox signaling by dietary polyphenols. Biochem Pharmacol 2006;72:1439-52.

8. Zern TL, Fernandez ML. Cardioprotective effects of dietary polyphenols. J Nutr 2005;135:2291-4.

9. Yu L, Haley S, Perret J, Harris M. Comparison of wheat flours grown at different locations for their antioxidant properties. Food Chem 2004;86:11-6

10. Brindzová L, Certík M, Rapta P, Zalibera M, Mikulajová A, Takácsová $\mathrm{M}$. Antioxidant activity, $\beta$-glucan and lipid contents of oat varieties. Czech J Food Sci 2008;26:163-73.

11. Singh KA, Chanu KL, Snehalatha V. Screening of antimicrobial, antioxidant and anticancer activity of Schizophyllum commune and
Auricularia auricula. Int J Adv Sci Res Publ 2018;4:8-12.

12. Özcan Ö, Ertan F. Beta-glucan content, antioxidant and antimicrobial activities of some edible mushroom species. Food Sci Technol 2018; 6:47-55

13. Zechner-Krpan V, Petravic-Tominac V, Gospodaric I, Sajli L, Dakovic S, Filipovic-Grcic J. Characterization of b-glucans isolated from Brewer's yeast and dried by different methods. Food Technol Biotechnol 2010;48:189-97.

14. Limberger-Bayer VM, de Francisco A, Chan A, Oro, T, Ogliari PJ, Barreto PL. Barley b-glucans extraction and partial characterization. Food Chem 2014;154:84-9.

15. Ahmad A, Anjum FM, Zahoor T, Nawaz H, Ahmed Z. Extraction and characterization of d-glucan from oat for industrial utilization. Int J Biol Markers 2010;46:304-09.

16. Wang Y, Ahmed Z, Feng W, Li C, Song S. Physicochemical properties of exopolysaccharide produced by Lactobacillus kefiranofaciens ZW3 isolated from tibet kefir. Int J Biol Markers 2008;43:283-8.

17. Mikkelsen MS, Jespersen BM, Moller BL, Laerke HN, Larsen FH, Engelsen SB. Comparative spectroscopic and rheological studies on crude and purified soluble barley and oat b-glucan preparations. Food Res Int 2010;43:2417-24.

18. Wang SS, Wang DM, Pu WJ, Li DW. Phytochemical profiles, antioxidant and antimicrobial activities of three Potentilla species. BMC Complement Altern Med 2013;13:321 